\title{
The Impact of a Teacher-Based Positive Education Intervention on Student Wellbeing Literacy
}

\author{
Lea Waters $^{1}$ (iD) and Matthew Charles Higgins ${ }^{2}$
}

\begin{abstract}
Over the past decade, research has consistently found that positive education interventions have a beneficial effect on mental health outcomes for students, such as improvements in life satisfaction and reduction of anxiety. While it is encouraging to see these changes in student mental health, the research has not yet adequately explored whether positive education interventions change a student's understanding of wellbeing itself. Wellbeing literacy is a new construct within the field of positive education and is defined as the ability to understand the concept and language of wellbeing. This study examines whether student language and understanding of wellbeing changes following a teacher-based intervention in positive education. Students across grades five, six and seven (ages 11-13; $n=231$ ) from three Australian schools provided brief written descriptions of their understanding of wellbeing before and after their teachers undertook an eight-month positive education intervention. Thematic analysis was used as the methodological tool to analyze student language and understanding of wellbeing. Inferential frequency-based statistical analyses were used to compare the pre-intervention and post-intervention responses. The results revealed that student understanding of wellbeing evolved in four key ways to become more: (1) detailed; (2) strength based; (3) expanded/multidimensional; and (4) relational. Post-intervention understanding of wellbeing was significantly more likely to include aspects of emotional management, strengths, coping, mindfulness and self-kindness. Implications, limitations and future directions are discussed.
\end{abstract}

Keywords: Positive education, student wellbeing, wellbeing literacy, intervention, teacher practice, qualitative research

Over the last two decades, youth mental illness has reached alarming rates globally (De Girolamo et al., 2012; Eyre \& Thapar, 2014; Frigerio et al., 2009; Kessler et al., 2001; Kieling et al., 2011; Lawrence et al., 2015). The COVID19 global pandemic and its associated restrictions and disruptions have further compromised the mental health of young people, with sharp rises in depression, anxiety and post-traumatic stress disorder (PTSD) across many countries (Arslan \& Y1ldırım, 2021; Guo et al., 2020; Kassim et al., 2021; Liang et al., 2020; Marques de Miranda et al., 2020; Yeasmin et al., 2020; Zhou et al., 2020).

As a response to the growing rates of youth mental illness occurring before and during the pandemic, numerous international organizations are calling for schools to play an active role in preventing youth distress and promoting youth wellbeing including the World Health Organization (WHO), the World Bank, the United Nations, the Organisation for Economic and Co-operative Development (OECD) and United Nations Educational, Scientific and Cultural Organization (UNESCO) (Helliwell, Layard \& Sachs, 2013; Learning Metrics Task Force, 2013; WHO \& UNESCO, 2018; WHO et al., 2000, 2021). For example, WHO states that focus on student wellbeing must be a top priority during the COVID-19 crisis (WHO, 2020). Prior to the crisis, and even more relevant today, the OECD (2015, p. 32) stated that "[p]erhaps the ultimate goal of education policy makers, teachers, and parents is to help children achieve the highest level of wellbeing possible."

In the current paper, wellbeing is conceptualized as a multidimensional construct (Forgeard et al., 2011; Seligman, 2018; Stutzer \& Frey, 2010) characterized by a profile of indicators that fall on the positive end of the mental health

\footnotetext{
${ }^{1}$ Centre for Wellbeing Science, Melbourne Graduate School of Education, University of Melbourne, Australia

${ }^{2}$ Division of Behavioral and Organizational Sciences, Claremont Graduate University, USA

Corresponding Author: Lea Waters, Centre for Wellbeing Science, Melbourne Graduate School of Education, University of Melbourne, Australia.

Email: L.Waters@unimelb.edu.au
} 
continuum (Keyes, 2007; Westerhof \& Keyes, 2010). Researchers have identified that youth wellbeing comprises many positive dimensions, including, but not limited to, happiness, life satisfaction, positive affect, meaning, mastery, hope, engagement and connection (Arslan, 2021; Kern et al., 2015, 2016; Lerner et al., 2009). In layperson's terms, wellbeing can be seen as "the combination of feeling good, functioning well and doing good" (Waters et al., 2017, p. 247).

The call for schools to teach both traditional academic skills and wellbeing skills is at the heart of positive education, a decade-old field that seeks to weaves positive psychology principles into teaching and learning to promote student wellbeing (Seligman et al., 2009; Slemp et al., 2017). Research has shown that positive education interventions are generally successful in building student wellbeing outcomes, including increases in life satisfaction, positive emotions, self-esteem, coping ability and emotional stability as well as reductions in anxiety, depression and stress (Owens \& Waters, 2020; Shoshani et al., 2016; Waters et al., 2015; Waters \& Loton, 2019). However, one outcome of positive education that has typically been overlooked is that of wellbeing literacy (Oades, 2017; Waters, Loton et al., 2021).

\section{Wellbeing Literacy: A Foundational Building Block for Student Mental Health}

Oades and Johnston (2017, p. 1) describe an individual's knowledge about wellbeing as "wellbeing literacy." In the same way that a person can be literate (i.e., have knowledge, be educated) in the arts, history or politics, a person can also be literate in wellbeing. Wellbeing literacy is a construct that reflects the intersection between the words that people use to describe wellbeing and the understanding they have of wellbeing. According to Oades et al. (2020), there is a two-way relationship between words and understanding in wellbeing literacy. The words people use about wellbeing shape their understanding of it. On the other hand, as an individual's understanding of wellbeing changes, the words they use to describe it change too. Put differently, words shape understanding and understanding shapes words and, in turn, the intersection between these two shape a person's experience of wellbeing. For example, affect labeling (i.e., the capacity to put words to one's emotions and inner experiences) has long been found to be a factor that significantly contributes to psychological healing in therapy (Jager et al., 2021), and has also been found to improve distress regulation in non-clinical samples (Constantinou et al., 2014). In education contexts, teaching emotional literacy to students has been found to improve self-confidence and interpersonal skills (Bracket et al., 2019; Weare, 2004). Conversely, low emotional literacy in students is a risk factor that increases their likelihood of psychological maladjustment, alcohol use, academic anxiety and somatic complaints (e.g., trouble sleeping, headaches) as well as reducing their ability to regulate distress after a stressful situation (Brown et al., 2021; Kashdan et al., 2010; Liau et al., 2003).

Given that the ability to describe and understand their own wellbeing is an important factor that shapes mental health outcomes for students, research into how wellbeing literacy can be fostered in schools is important. Indeed, Haddon et al. (2005, p. 5) called for research to examine how "a school enables members of its community to interact in ways that build an understanding of their own and others' emotions and to use this understanding to shape their actions." To this end, scholars have examined several ways in which wellbeing literacy can be fostered in schools, including circle time, positive psychology interventions, use of wellbeing language and training teachers in positive education.

Circle time is a group listening practice that provides students with the space and permission to talk about their feelings, explore moral topics and resolve conflict (Cefai et al., 2013). Research has shown that this classroom practice cultivates emotional literacy as evidenced by students developing a wider vocabulary about emotions, feeling more comfortable talking about their emotions, improving their ability to regulate their own emotions and becoming more adept at recognizing the emotional states of others (Coppock, 2007; Roffey, 2006; Tominey \& McClelland, 2011).

Holder et al. (2016) designed a student-based intervention that focused on happiness by placing "Walls of Wellbeing" (WOWs) around the student campus in two schools and inviting student to write their answers to the question "I feel happy when..." The WOWs allowed students to identify and talk about happiness with their teachers and other students. The students' written responses provided Holder and his colleagues with a qualitative data set of wellbeing literacy as it relates to happiness. Kindergarten and elementary school students described happiness as coming from relationships (e.g., friends, pets) and had an other-orientation (e.g., sharing, helping someone), while 
junior high students described happiness as coming from activities they undertake (e.g., reading, eating, gaming, music) and focused more on personal feelings (e.g., feeling proud, inspired).

A further avenue shown to influence wellbeing literacy in students is the use of teacher language. For example, research shows that the type of feedback teachers provide (using general language versus specific words) significantly influences whether students adopt a fixed or growth mindset - the understanding a student has about their own capacity for change (Cimpian et al., 2007; Zentall \& Morris, 2010). Similarly, Dweck (2008) found that the use of the word "yet" by teachers (e.g., "You don't know how to solve that equation, yet") was significantly predictive of a student's likelihood to stay motivated and persist through learning challenges. According to Dweck (2008), the inclusion of the term "yet" in the teacher's lexicon creates a path for future growth because it communicates to students the potential for improvement, learning and success.

It is not only the language of teachers that effects student wellbeing literacy, but also the language the students use themselves. Larson and colleagues (Larson, 1983; Larson \& Kleiber, 1993) as well as Heath (1991, 1993, 1999) have shown that peer language is a core factor in a teenager's understanding of themselves as having mastery and initiative. Larson's (2000) research found that students who took part in group-based extracurricular activities or community youth activities developed their own "operating language of initiative" (Larson, 2000, p. 171) and this change in language allowed them to show independence, create change and manage responsibility.

The research above suggests that circle time, student interventions (e.g., WOWs) and use of language (e.g., teacher and peer) are three important mechanisms that can be used to gain insight into and bolster various aspects of wellbeing literacy. Moreover, these studies have provided students with an opportunity to talk about and understand various dimensions of wellbeing, including emotions, happiness, mindset, motivation and initiative.

Waters (2021) developed a positive education intervention that trained teachers in wellbeing language and wellbeing classroom practices to investigate whether this could promote wellbeing literacy in the classroom. Across three time points of qualitative data collection teachers reported improvements in their own wellbeing literacy: "The major difference is the language I can now give to the students for them to better recognize and have words for their wellbeing and how it influences their behaviours and actions" (Waters, 2021, p. 148). They also reported improvements in the wellbeing literacy of their student: "Students have a broader vocabulary around emotions and it's allowing them to express themselves in a more open and honest way" (Waters, 2021, p. 148). Additionally, teachers in this study reported that the wellbeing practices had enhanced students' understanding of what wellbeing is and the ways they can influence their own mental health. To this end, the teachers reported outcomes such as students developing a wider emotional vocabulary; talking about and using their strengths more often; showing greater empathy towards their peers and expressing more gratitude to others. However, the study did not collect direct data from the students themselves and, instead, relied on teacher data.

According to Oades et al. (2020), wellbeing literacy is a skill that can be developed in young people given the right learning environment. The research above shows that circle time, positive psychology interventions for students, teacher/peer language and teacher-based positive education interventions form part of a learning environment that successfully fosters wellbeing literacy. The current study seeks to build on this knowledge and address two clear gaps in the literature. First, research to date has focused on specific dimensions of wellbeing literacy (i.e., emotions, happiness, mindset, motivation and initiative) but has not yet asked an open-ended question about wellbeing more broadly. By focusing on specific aspects of wellbeing, students can only provide narrow answers and thus cannot express the range of ideas they may have about wellbeing. While it has been validated that wellbeing is a multidimensional construct (Forgeard et al., 2011; Seligman, 2018; Stutzer \& Frey 2010) research to date has not provided a way for students to tell us if they understand wellbeing to be unidimensional or multidimensional and, if multidimensional, what dimensions are relevant to them. The current study will not focus on one aspect of wellbeing but will use an open-ended question about wellbeing that allows students to provide a range of answers.

Second, and related to this, much of the research has used adult-centric measurement such as researcher-designed surveys (e.g., Cimpian et al., 2007; Zentall \& Morris, 2010), standardized tests (e.g., Tominey \& McClelland, 2011), or teacher reports or teacher observation (e.g., Waters, 2021). According to Lansdown (2004, p. 5), research has too often "assessed children from an adult perspective and through an adult filtering process." This reliance on adult- 
centric data collection measures means that the language students themselves use to describe wellbeing has not been utilized as data. Given that wellbeing literacy is, at its core, about the words that young people use, it is vital that positive education researcher use "student voice" research methods (Cook-Sather, 2018) that directly collect the students' own descriptions of wellbeing.

In the current study, we aim to examine whether wellbeing literacy develops in students following a positive education intervention. The qualitative nature of this research means that specific hypotheses are not provided, rather an over-arching guiding research question is explored as follows: Does training teachers about positive education improve student wellbeing literacy?

\section{Method}

\section{Positive Education Intervention for Teachers: Visible Wellbeing}

Over the past 15 years, education researchers have advocated for a science-informed pedagogy of learning (Fischer et al., 2007) that involves training teachers how to use the science of learning to improve academic outcomes for students (Darling-Hammond et al., 2008; Hattie, 2008; Ritchhart et al., 2011).

Table I. SEARCH pathways and examples of positive education interventions for each pathway

\begin{tabular}{ll}
\hline Search Pathway & Description of Pathway \\
\hline Strengths & Pre-existing qualities that arise \\
& naturally, feel authentic, are \\
& intrinsically motivating to use and \\
& energizing
\end{tabular}

Emotional The ability to identify, understand, management and manage one's emotions Search Interventions Researched in Science Strength awareness: These interventions help students to identify their strengths, typically through surveys Strength use: These interventions help students set goals for how to put their strength into actions Strength spotting: These interventions teach students how to see when their peers are using strengths Emotional intelligence (EI): These interventions teach students how to perceive, understand, use, and regulate emotions Gratitude: Gratitude interventions help students to notice, appreciate, and acknowledge the positive in their lives

Attention and Ability to focus on inner aspects of awareness

Relationships

Coping

Habits and goals self (e.g., emotions) or on external stimuli (e.g., the teacher). Awareness refers to the ability to pay attention to a stimulus as it occurs

This pathway involves the skills required to build and support social relationships as well as capitalize on momentary social interactions

Coping is defined as constantly changing cognitive and behavioral efforts to manage demands

Habits are persistent patterns in decision making and action. Goals are formal aspirations that people aim for and are willing to invest effort in attaining
Meditation: Meditation is defined as the deliberate act of regulating attention through the observation of thoughts, emotions and body states. Meditation interventions in schools involve training a student's attention

Mindfulness: Mindful interventions help students to develop the skill of self-observation and to be dispassionate and compassionate about themselves in the present moment

Mentoring: Mentoring is a process by which a more experienced person provides a less experienced person with guidance, support, and care over an extended period

Peer support: peer-to-peer support enhances a sense of connectedness and belonging in the school

Resilience and coping: These interventions aim to help students develop the capacity for maintaining, recovering or improving mental health following life challenges

Goal interventions: These interventions teach students to set and strive for goals

Self-regulated learning (SRL) interventions: SRL interventions teach students the cyclical process of steps needed to persist through the learning process: self-evaluation, self-monitoring and goal setting along with strategy planning, implementation and monitoring 
Along the same lines, Waters (2021, p. 144) has argued for a "science-informed pedagogy for wellbeing" that involves training teachers how to use the science of positive education to improve wellbeing outcomes for students.

To this end, Waters (2015) developed a pedagogical intervention for teachers based on the science of positive education called Visible Wellbeing (VWB). Visible Wellbeing trains teachers in a language, framework and practices for seeing and building the wellbeing of their students. The evidence-based framework that underpins the VWB intervention is called SEARCH (Waters, 2019; Waters \& Loton, 2019). The SEARCH framework covers six overarching pathways to wellbeing: strengths, emotional management, attention and awareness, relationships, coping and habits, and goals. Teachers who are trained in the VWB intervention undertake a three-hour training module in each of the six SEARCH pathways. Table 1 provides a description of each of the six pathways together with examples of positive education interventions that map on to the pathways.

Using the principles of distributed learning (Downes, 2017) the VWB intervention was delivered over an eightmonth period (across Terms 1, 2 and 3) so that teachers had time to digest the learning from each training module and embed each of the SEARCH pathways into their classroom over time. As part of the intervention, teachers were provided with SEARCH-based activities that help students learn the language and skills for wellbeing. For example, strengths activities included students completing a strength survey and spotting strengths in their peers. Emotional management activities included identifying emotions through a mood-meter and playing emotions bingo.

\section{Sample and Procedure}

Two hundred and thirty-one students from fifth, sixth and seventh grades formed the final sample for this study (age range 11-13; 49\% female). Students were sourced from three Australian schools whose teachers had been involved in the positive education intervention.

At the beginning of the academic year, before the teachers began the positive education intervention, students were asked to log into an online Qualtrics page developed for the purposes of this study and type their name and a brief explanation of what they thought wellbeing was. At the end of the academic year, students were again asked to log on to the Qualtrics page and type their name and a brief explanation of wellbeing. Student names were used to match pre-intervention (time 1) and post-intervention answers (time 2), and the names were then removed from the data set and each matched pair of answers was given a code number. An $87 \%$ response rate was obtained at postintervention, with $13 \%$ of students from time 1 not entering an answer. Typical reasons for not completing the postintervention data collection included being absent, feeling unwell or relocating to a different school. Only students who completed both waves of data were included in the study sample.

Students' written narratives were chosen as the most suitable form of data collection method for this study given that the aim was to access students' own understanding of wellbeing to identify whether it changed before and after the teacher intervention. Although psychological surveys are the most common form of data obtained from students in positive education research (Waters \& Loton, 2019), we did not want to preimpose language and ideas about wellbeing on students by priming them through surveys. While many of the youth surveys used in positive psychology are self-report and, thus, give students autonomy in how they answer, the surveys are based upon adult conceptualizations of wellbeing that use predefined wellbeing language and researcher-created items. This researcher-centric approach means that the knowledge and experience a student has about wellbeing is shoehorned into adult language with no opportunity for students to express their own self-generated meanings of wellbeing. Using students' own written responses to the question "What do you think wellbeing is?" taps into the young person's own ideas and voice, thus providing a valid source of data for the aims of the current study.

Similar to Holder et al.'s (2016) research, we adopted the methodology of "short written narratives" (see also Czarniawska, 2004; Olesen \& Eskelinen, 2011). While longer forms of narrative have served as the traditional method of data collection in qualitative analysis, short written narratives are growing in popularity because of the rich insight that can be extracted from succinct responses (Blom \& Nygren, 2010; Riessman, 2008, Riessman \& Quinney, 2005). Short written narratives have the additional benefit of providing insight into student understanding without taking up too much class time. This latter, more practical consideration is important when working with schools as teachers, often, do not want to sacrifice too much class time for research projects. 


\section{Epistemological Position and Analytical Method}

The method chosen to analyze the data was thematic analysis (TA) (Braun \& Clarke, 2006; Clarke \& Braun, 2017). TA is a widely used method within the qualitative paradigm that identifies and interprets patterns of meaning across a data set (Braun \& Clarke, 2012). According to Clarke and Braun (2017, p. 297), "Researchers have used TA to explore a wide variety of experiential concerns within positive psychology," and is thus suitably aligned with our current study and its focus on wellbeing.

TA seeks to identify and analyze codes and themes emerging from participant answers. Codes are the smallest units of analysis - they capture notable features of the data and are the building blocks for the larger themes that emerge. A theme represents a patterned response that reflects underlying ideas and assumptions revealed by study participants that is repeated across the data set (Braun \& Clarke, 2012). While codes come from the direct words that participants use (e.g., the answer "wellbeing is about happiness and sadness" would gain the code "emotions"), themes are patterns of meaning that come from the way words are strung together by the participant (e.g., the answer "wellbeing is about happiness and sadness" would be classified under the theme of duality as the participant recognizes that both positive and negative emotions comprise the concept of wellbeing).

Braun and Clarke's (2006) six steps of TA were used as the analytical framework: data familiarization, generating initial codes, searching for themes, reviewing themes, naming themes and writing up the results section. Figure 1 illustrates the iterative process of the first four steps used to generate and determine the codes and themes arising from the students' written descriptions of wellbeing.

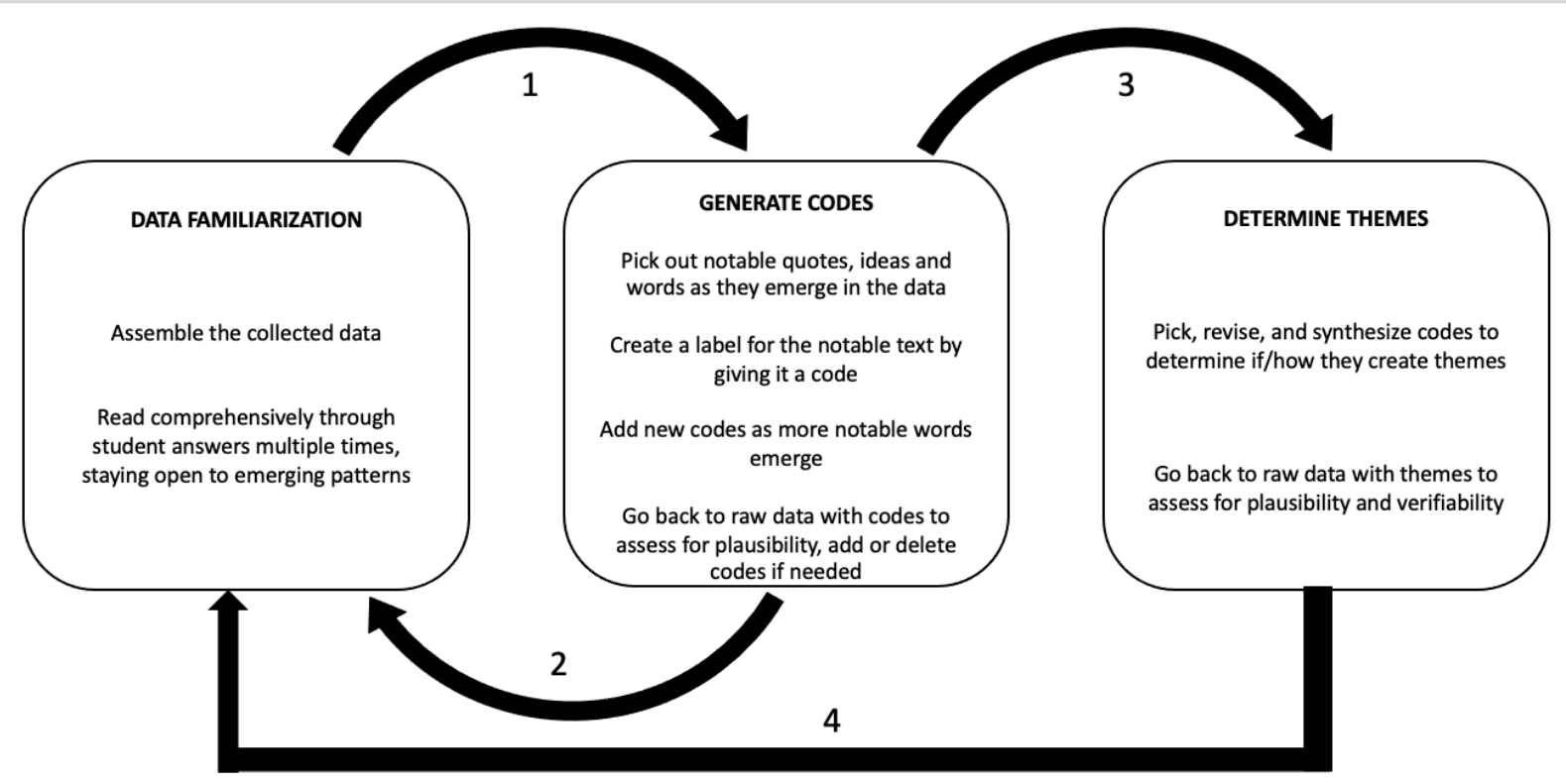

Figure I. Steps one to four of the TA process in the current study

Source: Based on Braun and Clarke (2006).

\section{Results}

\section{Descriptive analysis}

One way to examine whether the intervention had an impact on students' language and understanding of wellbeing is to examine whether the SEARCH wellbeing pathways -strengths, emotional management, attention and awareness, relationships, coping and habits and goals - were more evident in student descriptions of wellbeing postintervention. As such, answers were coded based on the SEARCH framework to compare data before and after the teacher intervention. In addition to coding answers along the six SEARCH pathways, two other categories were coded: "General" and "Don't know." The General category represented answers that talked about wellbeing in general terms (e.g., physical and mental health) without providing specific details. Examples of student answers that were coded into this category are as follows: "it means being well," "it's how you feel," and "I think wellbeing is what's good for me." ${ }^{1}$ The Don't know category was coded to represent the students who stated that they did not

\footnotetext{
${ }^{1}$ Note: Any typos and grammatical errors in students' answers remain uncorrected in the data analysis and in this paper.
} 
know, or were unclear, about the meaning of wellbeing. Examples of student answers that were coded into this category are as follows: "I don’t know," "Idk," "I'm not sure what wellbeing is," "I couldn't say," and "not sure."

As can be seen in Figure 2, wellbeing literacy changed considerably from pre-intervention to post-intervention with regard to student knowledge of the six SEARCH pathways. The most notable increases were in answers that contained references to coping and attention and awareness, as both of these pathways were absent at time 1, but formed $17 \%$ and $10 \%$, respectively, of all answers at time 2 . The other four SEARCH pathways were present at time 1, but all significantly increased at post-intervention, with the frequency of answers with regard to strengths increasing by $10 \%\left(\chi^{2}(1)=19.88, p<0.001\right)$; answers containing references to relationships increased by $10 \%\left(\chi^{2}\right.$ $(1)=19.88, p<0.001)$; emotional management increased by $4 \%\left(\chi^{2}(1)=10.08, p<0.001\right)$; and answers containing references to habits and goals increased by $2 \%\left(\chi^{2}(1)=10.40, p<0.001\right)$.

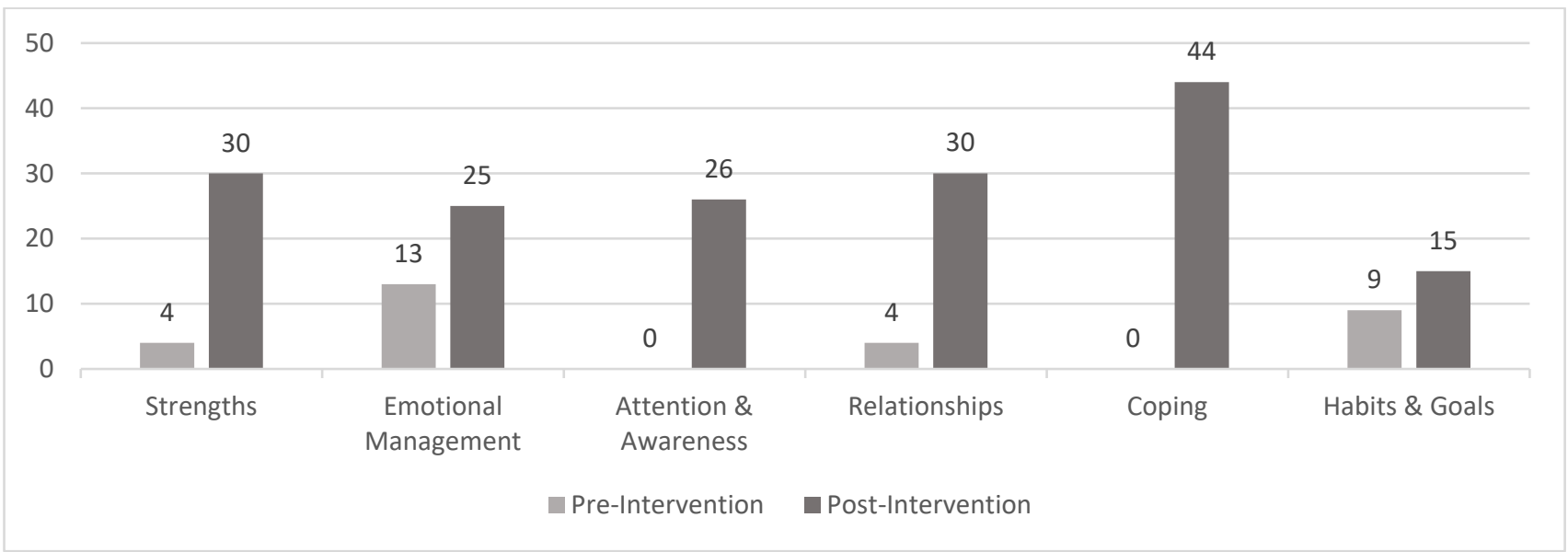

Figure 2. Student answers coded by SEARCH pathways at pre-intervention and post-intervention stages ${ }^{2}$

Figure 3 depicts the shifts over time in general descriptions of wellbeing as well as shifts in the number of students who stated that they did not know about wellbeing. General descriptions of wellbeing decreased by $40 \%\left(\chi^{2}(1)=\right.$ $26.58, p<0.001)$. The frequency of students who answered that they did not know dropped from 34 at preintervention to three at post-intervention - a $15 \%$ decrease $\left(\chi^{2}(1)=23.68, p<0.001\right)$.

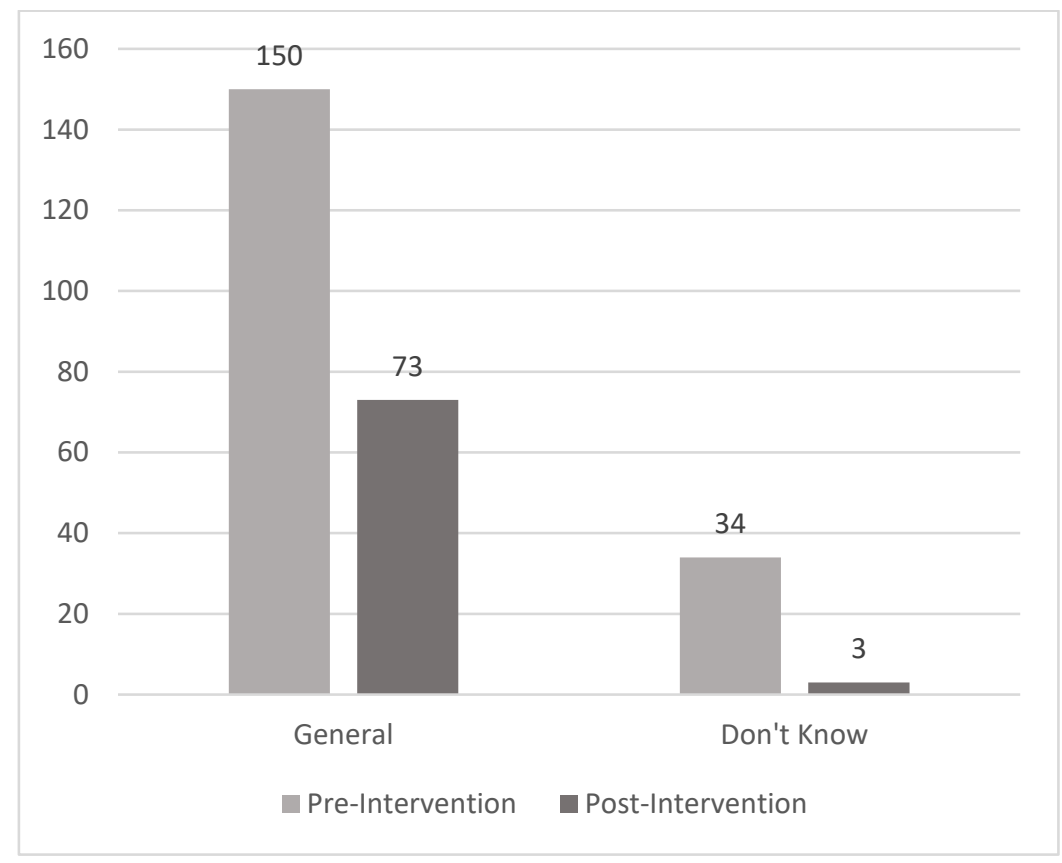

Figure 3. Student answers coded by general and don't know categories pre-intervention and post-intervention

\footnotetext{
${ }^{2}$ Note: Numbers represent the raw number of answers that map onto each SEARCH pathway; because a student answer might contain no SEARCH pathways, the sample size for codes is lower than the number of students contained in the study $(n=231)$.
} 
After exploring the raw numbers, we converted the data into percentages and displayed these in pie charts to observe the proportionality of the eight categories (see Figure 4). At post-intervention, the slices of the pie that contains SEARCH pathways became notably bigger, while the slices of the pie that contain general answers and don't know answers become smaller - thus, visually depicting how wellbeing literacy changes from pre-intervention to postintervention. We then combined the numbers for each the six pathways to get a total SEARCH score. At preintervention to total SEARCH score was 30 . At post-test this score had significantly increased to $170\left(\chi^{2}(1)=98\right.$, $p<0.001)$.
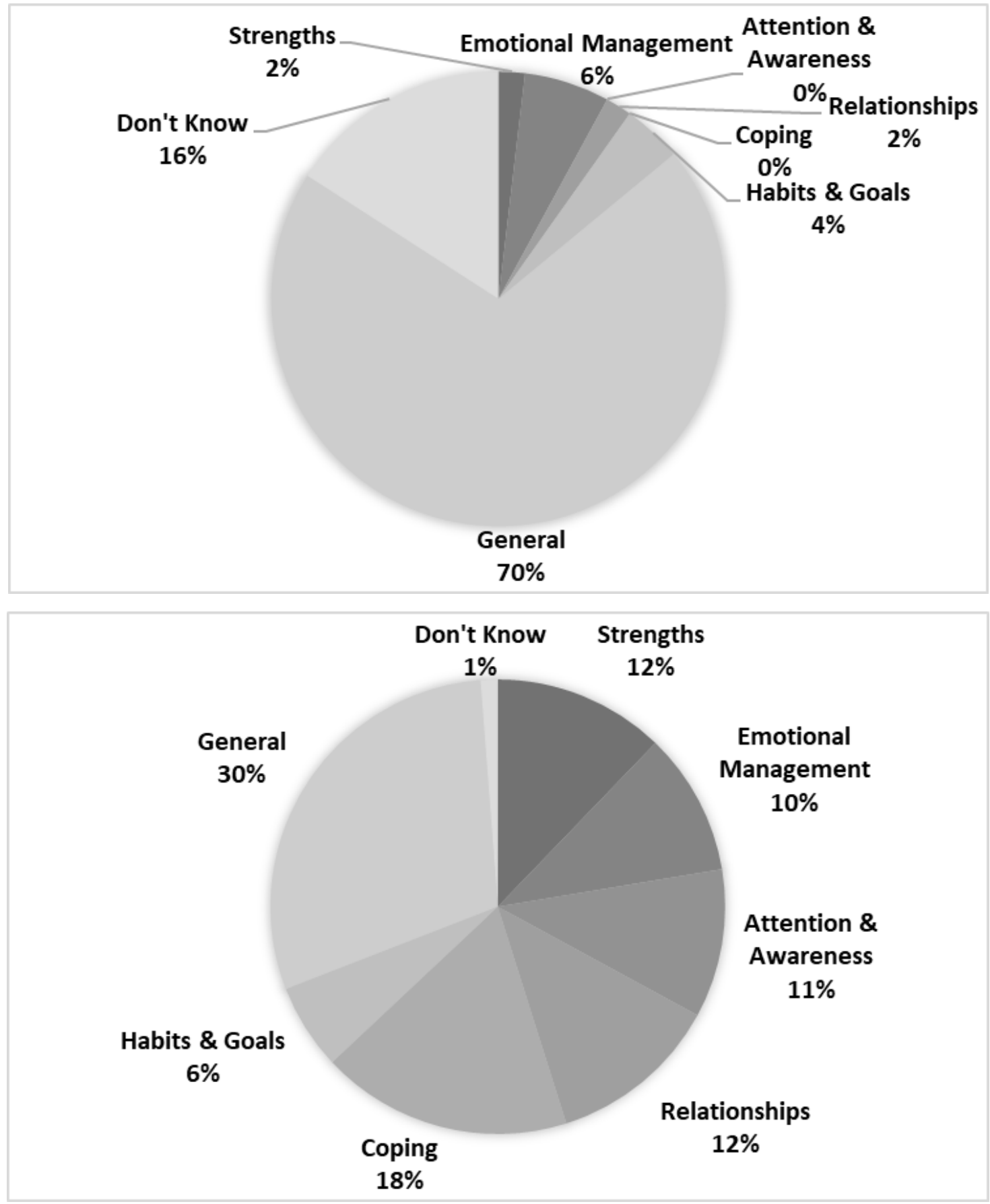

Figure 4. Percentage of answers coded in SEARCH pathways, general and don't know categories pre-intervention and post-intervention

Moving down from group-level comparisons of pre- and post-intervention answers to examine shifts for individual students also shows evidence of the effectiveness of the positive education intervention on students' understanding of wellbeing. Table 2 provides examples from students of how their understanding moved from a general or unclear answer before the intervention to become a more specific and sophisticated answer post-intervention. 
Table 2. Within-student examples of how wellbeing literacy changed from pre-intervention to post-intervention

\section{Post-intervention Answers}

"My understanding of wellbeing is that it is about awareness of your strengths and emotions" [strengths, emotional management, attention and awareness]
Pre-intervention Answers

Idk

Idk

Eating healthy

I think it is how you feel

Wellbeing is how you feel

Where you can take in or give advice to someone and be able to understand a bit more about Wellbeing is the mental health of a person yourself as a person truly

"Doing mindful and breathing to better control my emotions" [emotional management; attention and awareness]

"Relaxing, focusing, paying attention to my thoughts and creating positive thoughts" [attention and awareness]

"It's using your strengths, mine are zest, bravery, creativity, wisdom and love" [strengths]

"Wellbeing is looking after yourself and your emotions. Having the ability to control your emotions" [emotional management]

"Seeing a situation from different angles, learning how to cope by reframing a situation" [coping]

"Gratitude and being grateful, reframing hard times to see what you can learn from that experience, seeing the silver lining on the dark cloud. This doesn't mean you ignore the bad stuff but it means you know you can grow from it" [emotional management and coping]

Note: SEARCH pathways added in brackets at the end of the student answers.

\section{Thematic analysis \\ Codes}

Moving beyond categorical analysis, a TA of wellbeing literacy using Braun and Clarke's (Braun \& Clarke, 2006; Clarke \& Braun, 2017) iterative process was used to identify codes in the data. While the categorical analysis above followed a deductive method and used pre-set categories to code the data, the thematic analysis below was inductive, and codes were identified as they emerged from the data itself. This use of both deductive and inductive methods allows qualitative data to be triangulated by identifying common and divergent results using these two methods (Azungah, 2018).

At pre-intervention, the student responses for describing wellbeing generated seven codes. In order from most mentioned to least, the codes were: emotions, physical health, relationships, responsibilities, mind, enjoyment and safety. Descriptions of each of these codes are contained in Table 3. The inductive codes contained aspects of the SEARCH framework but went further. For example, safety and responsibilities are not aspects of the SEARCH framework yet were identified by students in their answers describing wellbeing. Additionally, the emotions code mentioned by students was broader than the SEARCH pathway of emotional management (see Table 1) as it contained general references to emotions without necessarily talking about how to manage emotions.

When comparing the codes at post-intervention with pre-intervention, definitions of wellbeing included significantly more references to strengths $(\chi 2(1)=19.88, \mathrm{p}<0.001)$ and relationships $\left(\chi^{2}(1)=3.4, \mathrm{p}<0.05\right)$. The largest increase was seen in a literacy of wellbeing that recognized mental state ( $8 \%$ increase) $(\chi 2(1)=22.05, \mathrm{p}<$ 0.001), including students talking about their minds, mindset and mindfulness. Perhaps related to this increase in references to mental state was the fact that the references to physical health in wellbeing literacy significantly decreased at time $2(\chi 2(1)=5.93, p<0.001)(18.1 \%$ decline $)$. The codes of emotions, responsibilities and enjoyment did not change from pre-intervention to post-intervention.

As well as shifts in existing codes over time, two new codes emerged at post-intervention: self-kindness and coping. The new code of self-kindness found at post-intervention comprised mentions of being kind or compassionate towards the self (e.g., "to calm yourself down when you are not feeling your best, to be compassionate to myself when I hav a bad day, self-kindness") and maps on to the emotional management and coping pathways of the SEARCH framework. 
Table 3. Wellbeing literacy codes at pre-intervention and post-intervention stages

\begin{tabular}{|c|c|c|c|c|}
\hline Code & Description & Example Answers from the Data Set & $\begin{array}{c}\text { Pre- } \\
\text { intervention } \\
n=257\end{array}$ & $\begin{array}{c}\text { Post- } \\
\text { intervention } \\
n=397\end{array}$ \\
\hline Physical health & $\begin{array}{l}\text { References to staying fit, } \\
\text { exercise, adequate sleep, eating, } \\
\text { staying hydrated, and direct } \\
\text { references to the body as vehicle } \\
\text { of wellbeing }\end{array}$ & $\begin{array}{l}\text { "It's about being active and staying fit and } \\
\text { healthy" } \\
\text { "Doing exercising and eating healthy food" }\end{array}$ & $70(27.2 \%)$ & $44(11.1 \%)$ \\
\hline Emotions & $\begin{array}{l}\text { References to emotion and/or } \\
\text { feelings, whether they are good } \\
\text { or bad }\end{array}$ & $\begin{array}{l}\text { "How are you feeling and if you are happy" } \\
\text { "It's about being happy and sad and } \\
\text { knowing that feelings come and go" }\end{array}$ & $\begin{array}{c}100 \\
(38.9 \%)\end{array}$ & $\begin{array}{c}123 \\
(31.0 \%)\end{array}$ \\
\hline Responsibilities & $\begin{array}{l}\text { References to pursuing goals, } \\
\text { organization, completing school } \\
\text { work, grades, classroom } \\
\text { behavior, including hygiene } \\
\text { and/or cleaning room }\end{array}$ & $\begin{array}{l}\text { "My understanding to that is understand } \\
\text { what I am doing and listen to teacher and } \\
\text { well behave" } \\
\text { "That never give up, be resilient and listen } \\
\text { to your parents and respect our teacher and } \\
\text { make good friend" }\end{array}$ & $21(8.1 \%)$ & $29(7.3 \%)$ \\
\hline Relationships & $\begin{array}{l}\text { References to relationships with } \\
\text { family, friends, peers, others, } \\
\text { animals and/or the earth }\end{array}$ & $\begin{array}{l}\text { "wellbeing is looking after each other and } \\
\text { watching their backs all the time when they } \\
\text { are in hear situations" } \\
\text { "How you feel and how you make other } \\
\text { feel, its based on your inner world and also } \\
\text { your relationships with others" }\end{array}$ & $34(13.2 \%)$ & $51(12.8 \%)$ \\
\hline Mental state & $\begin{array}{l}\text { References to the mind, mindset, } \\
\text { or mentality of self and/or others }\end{array}$ & $\begin{array}{l}\text { "My understanding of wellbeing is how you } \\
\text { are feeling and your mental state" } \\
\text { "Its about paying attention the inner } \\
\text { messages and having awareness about how } \\
\text { they change our actions" }\end{array}$ & $19(7.4 \%)$ & $61(15.4 \%)$ \\
\hline Enjoyment & $\begin{array}{l}\text { References to enjoying life, } \\
\text { small things in life, and overall } \\
\text { satisfaction }\end{array}$ & $\begin{array}{l}\text { "To maintain a level of enjoyment" } \\
\text { "Wellbeing is about being happy about your } \\
\text { life" }\end{array}$ & $4(1.6 \%)$ & $11(2.8 \%)$ \\
\hline Safety & $\begin{array}{l}\text { Includes references to safety, } \\
\text { being safe, and the safety of } \\
\text { others }\end{array}$ & $\begin{array}{l}\text { "The way you feel when you are around } \\
\text { people and feel safe" } \\
\text { "I guess it means the safety of a person" }\end{array}$ & $5(1.9 \%)$ & - \\
\hline Strengths & $\begin{array}{l}\text { References to knowing and/or } \\
\text { using one's strengths }\end{array}$ & $\begin{array}{l}\text { "Using your strengths in ways that make } \\
\text { you happy and be at your best" } \\
\text { "A persons wellbeing reflects how strong } \\
\text { they are and how they cope with situations } \\
\text { both mentally and physically by using their } \\
\text { strengths" }\end{array}$ & $4(1.6 \%)$ & $30(7.6 \%)$ \\
\hline Self-kindness & $\begin{array}{l}\text { References to being kind or } \\
\text { compassionate towards the self }\end{array}$ & $\begin{array}{l}\text { "Knowing how to be in alone but not feel } \\
\text { lonely, being your own best friend, feeling } \\
\text { self-contentment and showing self- } \\
\text { compassion" }\end{array}$ & - & $19(4.8 \%)$ \\
\hline Coping & $\begin{array}{l}\text { Direct references to coping or } \\
\text { dealing with challenges }\end{array}$ & $\begin{array}{l}\text { "Its knowing you can get back on your feet } \\
\text { if you get knocked down, coping is a big } \\
\text { part of wellbeing" } \\
\text { "We studied people who have had lots of } \\
\text { challenges like Gandhi and what coping } \\
\text { strategies helped them" }\end{array}$ & - & $29(7.3 \%)$ \\
\hline
\end{tabular}
size $(n=231)$; a higher number of answers mapped on to the codes at post-intervention $(n=397)$ than pre-intervention $(\mathrm{n}=257)$, which is evidence that wellbeing literacy had greater depth and dimensionality at time 2. 
References to the coping pathway at post-intervention included dealing with challenges (e.g., "its aiming high, setting goals, knowing you can try again if you fail the first time") and being resilient (e.g., "It's knowing about your emotions and learning to become resilient so you can cope with tough times"). Post-intervention answers also included using specific coping techniques such as breathing (e.g., "Wellbeing occurs at different levels and we can using coping things like star fish breathing if we are at the lowest level"; "We have been taught about mindfulness and about letting go of stress; our teacher showed us breathing tricks that calm us down").

\section{Themes}

The codes above are the smallest units of analysis (i.e., direct words) that were then used in the next step of TA as building blocks to identify themes. Themes represent a higher-order answer because they are formed though an inferred pattern that reflects an underlying assumption revealed by participants about wellbeing (Guest et al., 2012). Two themes emerged in student answers prior to the intervention: (1) dimensionality and (2) duality (see Table 4).

With regard to dimensionality, a pattern emerged in student answers reflecting wellbeing as either a unidimensional or multidimensional concept. Unidimensional conceptualizations of wellbeing contained only one code - for example: "Doing your work," "It's socializing and having friends" and "Sleeping a lot and eating vegetables." These quotes contain the codes responsibility, relationships and physical health, respectively, and each has only one code. Multidimensional answers included multiple codes. For example, "To be happy and to be a good person who is kind and helps others feel happy" was an answer that incorporated the codes of emotions and relationships. Similarly, "it's more than physical health it's also about your emotions and the way you think" has elements of physical health, emotions and mental state.

The theme of duality represents the way students depicted the positive and negative aspects of wellbeing. Answers were coded as singular if they contained only one end of the mental health continuum - either negative or positive. Answers were coded as dual if they contained both ends of the continuum. Examples of singular-positive answers included: "It's your feeling of happiness," "to maintain a level of enjoyment," and "my wellbeing is me feeling happy." Examples of singular-negative answers were typically reflected by wellbeing as the absence of something negative: "It's trying not to worry," "making sure you are not stressed or shy or anxious," and "not being mad and upset." Examples of dual answers included: "it's ALL of your emotions and that means you can be sad but you can also be happy and curious," "Emotions and feelings and your wellbeing is in three basic levels ok, not feeling ok, and angry," and "wellbeing comes from our emotions and these sit along a spectrum from negative to positive; we have lots of emotions each day."

At post-intervention, the themes of dimensionality and duality were still present. There was a significant change in dimensionality $\chi^{2}(1)=30.03, p<0.001$ ), with unidimensional answers significantly declining by $32.3 \%$ and multidimensional answers increasing by $39 \%$, suggesting that students' understanding of wellbeing had evolved to become more sophisticated after teachers had been trained in a positive education intervention. Duality was also significantly different between pre- and post-interventions $\left(\chi^{2}(2)=7.30, p<0.03\right)$. As this theme had three levels, post-hoc testing was conducted using Holm-Bonferoni adjustment to counteract the problem of multiple comparisons. The alpha level of $p<0.01(z=-2.64)$ indicated a significant decrease $(4.9 \%)$ in the singular-negative category at post-intervention.

At post-intervention, answers about wellbeing contained three new themes: agency, perspective and connectedness. With regard to agency, student understanding of wellbeing after their teachers' positive education intervention training included the ability to influence, control or regulate various aspects of their own wellbeing. For example, students wrote about wellbeing as "control over emotions" and "Wellbeing is important and can change." Other answers implied agency when they described wellbeing: "I have more choice over my emotions than I sometimes think."

The theme of perspective reflected students' views that wellbeing is part of the bigger picture in life, often depicted by students through use of metaphors to explain wellbeing: "your wellbeing is like the weather and you need to have awareness of your own barometer and know you can cope with the storms." Another student used a mathematical metaphor, stating that "[w]ellbeing is like an equation between your thoughts and your feelings and this equation determines whether your reactions are positive or negative." Wellbeing was also described as a type 
of fitness: "Wellbeing means mental and emotional health; it's like going to the gym but for your emotions to get fitter." Another metaphor of wellbeing was diet" "Eating good food and having a good 'mental' diet by watching what thoughts we eat."

The third post-intervention theme evident in student descriptions of wellbeing was the recognition that the multiple dimensions of wellbeing are interconnected, such that the students discussed how their thoughts influenced their emotions, or their relationships influenced their ability to cope, and so on - for example, "Wellbeing is about your body and mind and how they talk to each other." Other answers reflecting this latent theme include: "knowing how I feel when I feel it, knowing that my attention determines my wellbeing, too much screen time is not good, paying attention to the good things in my life," and "With wellbeing there is a link between your thoughts and your feelings so you can pay attention to the thought bubbles and make yourself happier." This is a shift from the pre-intervention answers where those students who did provide multidimensional answers of wellbeing did not mention, or show an understanding, that the dimensions were interconnected. However, as the new theme of connectedness was only identified by $16.3 \%$ of the students, it was not a theme that a majority of students mentioned.

Table 4. Wellbeing literacy themes identified students' answers at pre-intervention and post-intervention

\begin{tabular}{llcc}
\hline Themes & & & \\
\cline { 3 - 4 } & & Pre & Post \\
& & $n=307$ & $n=506$ \\
\hline Dimensionality & Unidimensional & $144(46.9 \%)$ & $74(14.6 \%)$ \\
& Multidimensional & $63(20.5 \%)$ & $102(20.1 \%)$ \\
Duality & Singular-positive & $67(21.8 \%)$ & $59(11.7 \%)$ \\
& Singular-negative & $17(5.5 \%)$ & $3(0.6 \%)$ \\
& Positive and negative & $16(5.2 \%)$ & $14(2.8 \%)$ \\
Agency & & - & $118(23.3 \%)$ \\
Perspective & & - & $87(17.2 \%)$ \\
Connectedness & & - & $49(9.7 \%)$ \\
\hline
\end{tabular}

Figure 5 depicts all codes and themes that emerged from the data at pre-intervention and post-intervention stages to provide a visual overview of the results.

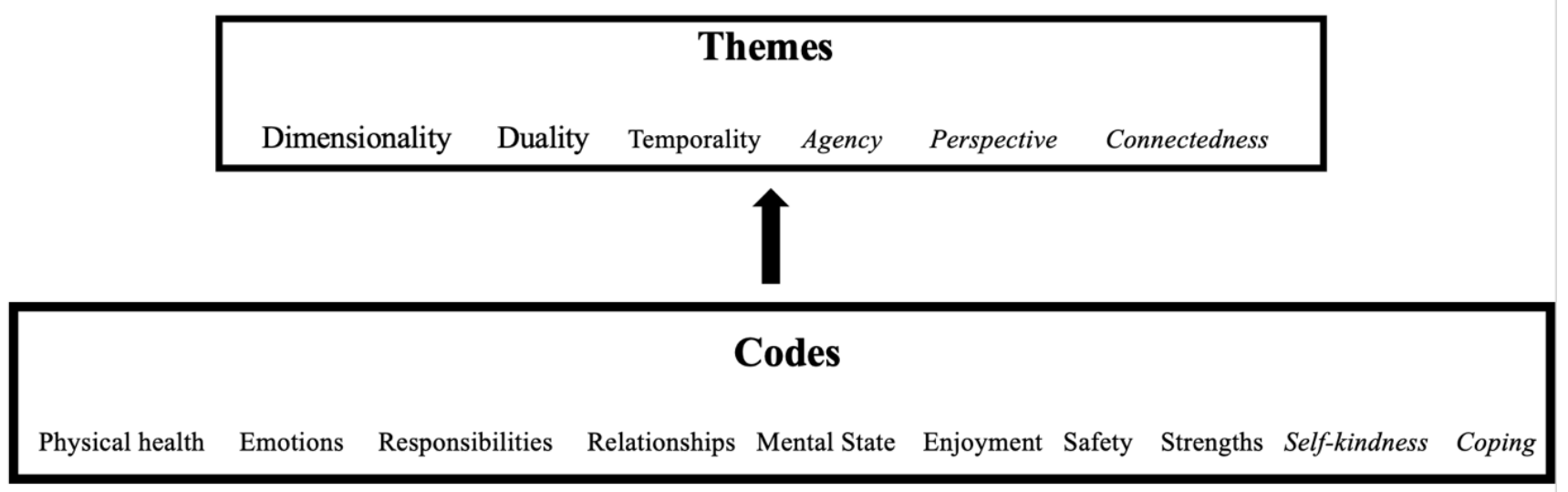

Figure 5. Overview of pre-intervention and post-interventions codes and themes

Note: Codes and themes in italics were present only at post-intervention.

\section{Discussion}

Youth mental illness has been a persistent global issue for the past two decades (Kessler et al., 2001), with distress and illness rates being amplified during the COVID-19 pandemic (Kassim et al., 2021; Marques de Miranda et al., 2020). Burke and Arslan (2020, p. 137) argue, however, that COVID-19 could "become a springboard for positive change, especially in schools that draw on positive education research to...foster students' social-emotional health." Indeed, positive education has played a key role in the prevention of student mental illness (i.e., psychopathology and distress) and the promotion of student wellbeing (i.e., indicators on the positive end of the mental health spectrum) both in pandemic times (Arslan \& Burke, 2021; Malboeuf-Hurtubise et al., 2021; Waters, Allen, et al. 
2021) and pre-pandemic (Waters, 2011; Owens \& Waters, 2020). Positive education interventions have been shown to contribute to a range of youth mental health outcomes such as improvement in life satisfaction, hope and selfesteem, together with reductions in depression, stress and anxiety (Waters \& Loton, 2019).

Various scholars have also argued that positive education interventions should also be examined for how they can build wellbeing skills and capabilities (Adler, 2017; Waters et al., 2017), as it is these capabilities that endure postintervention and allow positive mental health outcomes to be sustained over time. One core capability put forward by Oades and colleagues (Oades, 2017; Oades \& Johnston, 2017; Oades et al., 2020) is that of wellbeing literacy, defined as the language and understanding of wellbeing. The current study examined whether students' language and understanding of wellbeing changed following an intervention that trained teachers on the core principles of positive education.

The ability to describe and understand one's own wellbeing is an important factor that shapes mental health outcomes for students and adults alike (Bracket et al., 2019; Constantinou et al., 2014; Jager et al., 2021; Weare, 2004). As such, Mashford-Scott et al. (2012) and Waters et al. (2021) posit that knowledge of how young people subjectively experience wellbeing is a foundational step in better supporting student wellbeing. In addition, King et al. (2005) reason that teachers are more likely to have a positive impact on student wellbeing if they can connect with students by speaking the student's own language. King et al. $(2005$, p. 96) further add that using words that have "ecological validity" for youth is a requirement for "translating developmental science into policies and programs...to support thriving among youth."

Despite the benefits that can be gained though understanding and using students own literacy about wellbeing, Fattore et al. (2009, p. 58) assert that "[1]ittle is known about what children and young people identify as well-being, what it looks like and the factors which affect their sense of it." One reason for this gap is that research tools used in positive education are typically researcher-designed surveys or parent/teacher reports - neither of which allow young people to use their own words. Given that wellbeing literacy is, at its core, about the words people use, we argue that "student voice" research methods (Cook-Sather, 2018) are the most appropriate way to assess student wellbeing literacy. The current study collected written answers by students, analyzed with TA, to directly identify the students' own descriptions of wellbeing. Furthermore, while earlier research has focused on specific dimensions of literacy such as emotions, happiness or mindset, we eschewed that research trend and instead cast a broad net to examine how students express their understanding of wellbeing more generally.

Results from this study found that wellbeing literacy in students grew significantly after their teachers had undertaken a positive education intervention. Teachers were trained in the science and practice of wellbeing using the SEARCH framework (Waters, 2019; Waters \& Loton, 2019) and were shown how to implement positive education language and practices in the classroom. When this occurred, post-intervention student literacy evolved in four key ways. Specifically, it became more: (1) detailed; (2) strength based; (3) expanded; and (4) relational.

With regard to wellbeing literacy becoming more detailed, while more than half $(53 \%)$ the students at preintervention had a generic understanding of wellbeing (e.g., "wellbeing is being well"; "it's how you feel"). At time 2 , students had developed a more in-depth understanding of wellbeing and were significantly more likely to describe wellbeing using aspects of the SEARCH framework. Post-intervention answers also saw a shift away from describing wellbeing as a form of physical health to an understanding that wellbeing is more about emotions and one's mental state. Adding to this, the trend of seeing wellbeing as a deficit-oriented construct - in other words, the absence of something negative (e.g., "It's trying not to feel tired and not to feeling stressed") - was significantly reduced at post-intervention, with singular-negative answers significantly declining.

Both the deductive and inductive analyses found that student understanding of wellbeing became more strength based at post-intervention (e.g., "I think it is like the happiness inside your self and the strengths you have"). A significantly higher proportion of students discussed their own strengths, the strengths of others and how strengths support wellbeing at post-intervention. Moreover, student answers revealed an understanding that they have multiple strengths they can draw upon and that using their strengths helps them to be a good friend, enjoy life and to cope with stress. In addition to directly talking about using their strengths as part of wellbeing (e.g., "Using your strengths to make the most of your day") and citing specific strengths (e.g., "Is about kindness and perseverance 
and strengths like love and creativity"), there was an understanding that taking a strength-based approach helps to boost wellbeing (e.g., "You can get happy by using your strengths and your strengths can make you resilient"). Perhaps another indirect indicator of this shift towards a strength-based understanding of wellbeing can be seen in the fact that singular-negative descriptions of wellbeing decreased at post-intervention showing that fewer students were defining wellbeing as the absence of something negative, meaning that, proportionally speaking, more students were taking a strength-based approach and seeing wellbeing as the presence of something positive.

Aligned with the strength based approach, wellbeing literacy at post-intervention reflected student views that agency was a key aspect of wellbeing - a theme that was not present at pre-intervention. It seems that, as teachers embedded wellbeing language and practices into the classroom, students learnt that they had more control over their own wellbeing than they initially believed. The students' post-intervention understanding of wellbeing as something that is strength based and agentic aligns with psychological research that supports the benefits of taking a strength-based approach with students (Proctor et al., 2011; Quinlan et al., 2015).

This newly formed understanding of the multiple ways to use their strengths is reflective of a broader trend in the current data set showing that wellbeing literacy expanded between pre- and post-intervention to become more multidimensional. At the individual student level, unidimensional answers (i.e., answers that contained only one code) declined by $32.3 \%$. Collectively, several new codes and themes were incorporated into descriptions of wellbeing at post-intervention.

The new code of coping at time 2 suggests that student understanding of wellbeing increased beyond wellbeing as "being well" or "feeling good" to that of "knowing you can get back on your feet if you get knocked down, coping is a big part of your wellbeing." For a smaller number of students (13\%), their comprehension of wellbeing had also expanded so that they understood the connectedness and inter-relationships between the multiple dimensions of wellbeing in ways that allowed them to see that the way they thought (code $=$ mental state) influenced the way they felt (code $=$ emotions) or that their relationships with others were a big influence on their own wellbeing.

Another indicator that students' understanding of wellbeing expanded following their teachers' training in positive education was the new theme of perspective emerging time 2. In particular, the use of metaphors in post-intervention answers shows the students' ability to think about wellbeing in abstract ways. Here we see a nice balance of wellbeing literacy becoming simultaneously more detailed yet abstract yet and also more expanded yet refined, and in both of these evolutions the students had moved away from generic, unidimensional conceptualizations.

Relationality is the fourth major way in which wellbeing literacy was seen to evolve from pre-intervention to postintervention. The inclusion of relationships as part of students' understanding of wellbeing significantly increased in both the deductive and inductive analyses. At post-intervention, students understood the bi-directional nature of relationships and wellbeing. They demonstrated an understanding that relationships are needed for their own wellbeing (e.g., "I play with my friend to be happy") and that they can contribute to the wellbeing of others (e.g., "wellbeing is being kind, caring and showing love"). The wisdom of these students, that relationships are a key part of wellbeing, is reflected in decades of psychology research (e.g., Baumeister \& Leary, 1995).

Self-kindness was a new code that emerged at time 2 and can be seen as a specific type of relationship with the self that has been shown to reduce psychological distress and improve mental health (Bluth et al., 2016; Stallman et al., 2018). The fact that this was not a code mentioned in students' answers before the teacher intervention suggests that the positive intervention helped students develop an understanding of, and practices for, self-kindness. These are skills and practices that can be continued to be used by the students as they move through their school journey and into adulthood. The same can be said for many of the ways in which wellbeing literacy matured in these students from pre-intervention to post-intervention, including using their strengths, managing their emotions, drawing on their agency and investing in relationships - all of which will help students sustain positive mental health outcomes over the longer term. These results show the benefits of a positive education intervention in enhancing students' wellbeing literacy.

\section{Implications}

According to Haddon et al. (2005, p. 5), wellbeing literacy is "not a capacity that is either present or absent in the individual, but rather is a potential in everyone that is not solely dependent upon the individual but also upon the social context in which the individual is located." This idea is supported in the current study, which has shown that 
wellbeing literacy in students became more detailed, strength-based, exapnded and relational after teachers introduced wellbeing language and practices into the classroom. The study aligns with calls by Allison et al. (2020) and Ciarrochi et al. (2016) that positive education interventions need to be designed to positively change context as well as deliver positive content.

The words and descriptions provided by students in the current study can be used as a resource to improve what King et al. (2005, p. 96) refer to as "ecological validity" to assist teachers in the ways they converse with students about wellbeing, as well as assist researchers to design effective positive education interventions. For example, we call for the explicit use of student voice when designing such programs. As stated by Ben-Arieh (2010, p. 135), children's daily life "is something that children know the most about." Including students in the co-design of wellbeing programs and using student-generated language is an empowering process that, in itself, will build student wellbeing irrespective of the content delivered by the program (Mäkelä et al., 2014). Using students to help codesign the interventions also aligns with the theme of agency that was mentioned by approximately one-third of the students at post-intervention as playing an important role in wellbeing.

With regard to the "what" of the design, the current study suggests that students will respond to programs that cover topics such as emotions and enjoyment, mental state and coping, relationships and self-kindness. Moreover, the data suggests that strength-based approaches will be well received by students. The SEARCH framework was also shown to be an effective framework for the design of positive education intervention and students demonstrated that they were able to learn about the six SEARCH pathways and incorporate these into their language and understanding of wellbeing.

\section{Limitations and Future Research}

The current study addressed several gaps in the existing literature by deductively and inductively exploring the topic of wellbeing literacy in students. As the topic of wellbeing literacy is relatively new, the current study provides an important exploration into how students understand and talk about their own wellbeing following a teacher-based positive education intervention. However, the current study contained limitations to its generalizability.

First, there was no control group, which would have provided a more solid test of the degree to which the positive education intervention created changes in wellbeing literacy. For example, it may be argued that the evolution of wellbeing literacy seen in the current students has occurred as part of the natural maturation process for 11-13-yearolds over the eight-month time period. However, given the significant increase in SEARCH-specific language demonstrated at post-intervention, it seems reasonable to assume that the shifts in wellbeing literacy were more due to the positive education language and the practices introduced into classes during the intervention than naturally occurring age-related changes.

Second, the sample itself may have influenced the results. For example, the age range in this study was 11-13 and this might be an age group that is more or less receptive to teacher influence on wellbeing literacy compared to younger or older age groups. If this is the case, then the capacity for positive education interventions to create change in wellbeing literacy for students across different ages still needs to be evaluated. That being said, Waters (2021) examined the effect of a teacher-based positive education intervention in a K-12 (from kindergarten to 12th grade) school using teacher report, and age did not emerge as a theme that prevented or promoted the likelihood of wellbeing literacy being developed. Although the words and understanding of wellbeing literacy were age related, the capability to improve in wellbeing literacy was present across all ages. However, as this is only one study, further research is needed to examine whether and how age may influence a student's ability to develop wellbeing literacy.

The limitations outlined above may restrict the generalizability of the results. However, it must be made clear that "generalizability" is not the core principle or goal to which qualitative research holds itself accountable (Given, 2008). Instead, external validity is assessed based upon the "confirmability" of the findings. Miles and Huberman (1994) argue that qualitative analysis that credible, defensible, and able to withstand alternative explanations is deemed as "confirmable. Given the ways in which the findings from our data support and extend past research, the student-centric way in which we obtained wellbeing literacy data, and the fact that we have explored alternative explanations, we are confident that the study findings are credible, defensible and warranted. 
Notwithstanding, we call for replication of the findings in future samples using a variety of research designs and methods across a range of ages to confirm whether and how wellbeing literacy can be built up as a capability in schools.

\section{Conclusion}

Schools are playing an increasingly important role in society not only as academic institutions but also as wellbeingenhancing institutions (Waters et al., 2017). The need for schools to foster wellbeing capabilities in students is paramount given the current pandemic crisis (Stewart et al., 2021) and the fact that research on prior pandemics reveals that mental illness spillover effects continue for some time after a pandemic is resolved (Sprang \& Silman, 2010). One capability that may prove to be highly beneficial is that of wellbeing literacy. The way in which students understand and talk about their own wellbeing is an important predictor of mental health, yet only limited research has investigated how this capability can be promoted. The results of the current study show that training teachers in positive education and having them embed wellbeing language and practices into their classrooms helped to evolve student wellbeing literacy so that it became more detailed, strength based, expanded/multidimensional and relational. We hope that this study inspires future "youth voice" research in the field of positive education.

\section{Ethical Standards}

\section{Compliance with Ethical Standards}

All study procedures involving human participants followed institutional and/or national research committee ethical standards and the 1964 Helsinki declaration and its later amendments or comparable ethical standards.

\section{Author Contributions}

The authors developed the concept for this manuscript, carried out the literature search, critically analyzed the data, wrote the manuscript, and proofread it.

\section{Declaration of Conflicting Interests}

The author(s) declared no potential conflicts of interest with respect to the research, authorship, and/or publication of this article.

\section{Funding}

The author(s) received no financial support for the research, authorship, and/or publication of this article.

\section{Data Availability}

The datasets generated during and/or analyzed during the current study are available from the corresponding author on reasonable request.

ORCID

Lea Waters@https://orcid.org/0000-0003-3648-2358

Received: October 13, 2021

Accepted: November 6, 2021

Published Online: November 23, 2021

\section{References}

Adler, A. (2017). Well-being and academic achievement: Towards a new evidence-based educational paradigm. In M. White, G. Slemp \& A. Murray (Eds.), Future directions in well-being (pp. 203-208). Springer.

Allison, L., Waters, L., \& Kern, M. (2020). Flourishing classrooms: Applying a systems-informed approach to positive education. Contemporary School Psychology. Advance online publication. https://doi.org/10.1007/s40688-019-00267-8

Arslan, G. (2021). Psychological well-being in college students: Psychometric properties of the Brief Inventory of Thriving (BIT) and the Comprehensive Inventory of Thriving (CIT). Journal of School and Educational Psychology, 1(1), 6-16. https://doi.org/10.47602/josep.v1i1.6

Arslan, G., \& Burke, J. (2021). Positive education to promote flourishing in students returning to school after COVID-19 closure. Journal of School and Educational Psychology, 1(1), 1-5. https://doi.org/10.47602/josep.v1i1.3 
Arslan, G., \& Y1ldırım, M. (2021). Perceived risk, positive youth-parent relationships, and internalizing problems in adolescents: Initial development of the Meaningful School Questionnaire. Child Indicators Research, 14(5), 1911-1929. https://doi.org/10.1007/s12187-021-09841-0

Azungah, T. (2018). Qualitative research: Deductive and inductive approaches to data analysis. Qualitative Research Journal, 18(4), 383-400. https://doi.org/10.1108/QRJ-D-18-00035

Baumeister, R. F., \& Leary, M. R. (1995). The need to belong: Desire for interpersonal attachments as a fundamental human motivation. Psychological Bulletin, 11(3), 497-529. https://doi.org/10.4324/9781351153683-3

Ben-Arieh, A. (2010). From child welfare to children well-being: The child indicators perspective. In S. B. Kamerman, S. Phipps \& A. Ben-Arieh (Eds.), From child welfare to child well-being: An international perspective on knowledge in the service of policy making (pp. 129-142). Springer.

Blom, B., \& Nygren, L. (2010). Analysing written narratives: Considerations on the "code-totality problems." Nordic Journal of Social Research, 1, 1-20. https://doi.org/10.15845/njsr.v1i0.66

Bluth, K., Roberson, P. N. E., Gaylord, S. A., Faurot, K. R., Grewen, K. M., Arzon, S., \& Girdler, S. S. (2016). Does self-compassion protect adolescents from stress? Journal of Child and Family Studies, 25(4), 1098-1109. https://doi.org/10.1007/s10826-015-0307-3

Brackett, M. A., Bailey, C. S., Hoffmann, J. D., \& Simmons, D. N. (2019). RULER: A theory-driven, systemic approach to social, emotional, and academic learning. Educational Psychologist, 54(3), 144-161. https://doi.org/10.1080/00461520.2019.1614447

Braun, V., \& Clarke, V. (2006). Using thematic analysis in psychology. Qualitative Research in Psychology, 3(2), 77-101. http:// doi.org/10.1191/1478088706qp063oa

Braun, V., \& Clarke, V. (2012). Thematic analysis. In H. Cooper, P. M. Camic, D. L. Long, A. T. Panter, D. Rindskopf \& K. J. Sher (Eds.), APA handbook of research methods in psychology, Vol. 2. Research designs: Quantitative, qualitative, neuropsychological, and biological (pp. 57-71). American Psychological Association.

Brown, B. A., Goodman, F. R., Disabato, D. J., Kashdan, T. B., Armeli, S., \& Tennen, H. (2021). Does negative emotion differentiation influence how people choose to regulate their distress after stressful events? A fouryear daily diary study. Emotion. Advance online publication. https://doi.org/10.1037/emo0000969.supp

Burke, J. \& Arslan, G. (2020). Positive education and positive school psychology during COVID-19 pandemic. Journal of Positive School Psychology, 4(2), 137-139. https://doi.org/10.47602/jpsp.v4i2.243

Cefai, C., Ferrario, E., Cavioni, V., Carter, A., \& Grech, T. (2013). Circle time for social and emotional learning in primary school. Pastoral Care in Education, 32(2), 116-130. https://doi.org/10.1080/02643944.2013.861506

Ciarrochi, J., Atkins, P. W., Hayes, L. L., Sahdra, B. K., \& Parker, P. (2016). Contextual positive psychology: Policy recommendations for implementing positive psychology into schools. Frontiers in Psychology, 7, 1561. https://doi.org/10.3389/fpsyg.2016.01561

Cimpian, A., Arce, H.-M. C., Markman, E. M., \& Dweck, C. S. (2007). Subtle linguistic cues affect children's motivation. Psychological Science, 18(4), 314-316. https://doi.org/10.1111/j.1467-9280.2007.01896.x

Clarke, V., \& Braun, V. (2017). Thematic analysis. The Journal of Positive Psychology, 12(3), 297-298, https://doi.org/10.1080/17439760.2016.1262613

Constantinou, E., Van den Houte, M., Bogaerts, K., Van Diest, I., \& Van den Bergh, O. (2014). Can words heal? Using affect labeling to reduce the effects of unpleasant cues on symptom reporting. Frontiers in Psychology, 5, 807. https://doi.org/10.3389/fpsyg.2014.00807

Cook-Sather A. (2018). Tracing the evolution of student voice in educational research. In R. Bourke \& J. Loveridge (Eds.), Radical collegiality through student voice (pp. 17-38). Springer.

Coppock, V. (2007). It's good to talk! A multidimensional qualitative study of the effectiveness of emotional literacy work in schools. Children \& Society, 21(6), 405-419. https://doi.org/10.1111/j.10990860.2006.00072.x

Czarniawska, B. (2004). Narratives in social science research: Introducing qualitative methods. SAGE Publications.

Darling-Hammond, L., Barron, B., Pearson, P. D., Schoenfeld, A. H., Stage, E. K., Zimmerman, T. D., Cervetti, G. N., \& Tilson, J. L. (2008). Powerful learning: What we know about teaching for understanding. Jossey-Bass.

De Girolamo, G., Dagani, J., Purcell, R., Cocchi, A., \& McGorry, P. D. (2012). Age of onset of mental disorders 
and use of mental health services: Needs, opportunities and obstacles. Epidemiology and Psychiatric Sciences, 21(1), 47-57. https://doi.org/10.1017/s2045796011000746

Downes, S. (2017). New models of open and distributed learning. In M. Jemni, K. Kinshuk \& M. Koutheair (Eds.), Open education: From OERs to MOOCs. Lecture notes in educational technology (pp. 1-22). Springer.

Dweck, C. (2008). Mindset: The new psychology of success. Ballantine Books.

Eyre, O., \& Thapar, A. (2014). Common adolescent mental disorders: Transition to adulthood. The Lancet, 383(9926), 1366-1368. https://doi.org/10.1016/s0140-6736(13)62633-1

Fattore, T., Mason, J., \& Watson, E. (2009). When children are asked about their well-being: towards a framework for guiding policy. Child Indicators Research, 2(1), 57-77. https://doi.org/10.1007/s12187-008-9025-3.

Fischer, K. W., Daniel, D. B., Immordino-Yang, M. H., Stern, E., Battro, A., \& Koizumi, H. (2007). Why mind, brain, and education? Why now? Mind, Brain, and Education, 1(1), 1-2. https://doi.org/10.1111/j.1751228X.2007.00006.X

Forgeard, M. J., Jayawickreme, E., Kern, M. L., \& Seligman, M. E. (2011). Doing the right thing: Measuring wellbeing for public policy. International Journal of Wellbeing, 1(1), 79-106. https://doi.org/10.5502/ijw.v1i1.15

Frigerio, A., Rucci, P., Goodman, R., Ammaniti, M., Carlet, O., Cavolina, P., De Girolamo, G., Lenti, C., Lucarelli, L., Mani, E., Martinuzzi, A., Micali, N., Milone, A., Morosini, P., Muratori, F., Nardocci, F., Pastore, V., Polidori, G., Tullini, A.,...Molteni, M. (2009). Prevalence and correlates of mental disorders among adolescents in Italy: The PrISMA study. European Child \& Adolescent Psychiatry, 18(4), 217-226. https://doi.org/10.1007/s00787-008-0720-x

Given, L. M. (2008). The SAGE encyclopedia of qualitative research methods. SAGE Publications.

Guest, G., MacQueen, K. M., \& Namey, E. E. (2012). Themes and codes. In G. Guest, K. M. MacQueen \& E. E. Namey, Applied thematic analysis (pp. 49-78). SAGE Publications.

Guo, J., Fu, M., Liu, D., Zhang, B., Wang, X., \& Van Ijzendoorn, M. H. (2020). Is the psychological impact of exposure to COVID-19 stronger in adolescents with pre-pandemic maltreatment experiences? A survey of rural Chinese adolescents. Child Abuse \& Neglect, 110, 104667. https://doi.org/10.1016/j.chiabu.2020.104667

Haddon, A., Goodman, H., Park, J., \& Crick, R.D. (2005). Evaluating emotional literacy in schools: the development of the School Emotional Environment for Learning Survey. Pastoral Care in Education, 23(4), 5-16. https://doi.org/10.1111/j.1468-0122.2005.00346.x

Hattie, J. (2008). Visible learning: A synthesis of over 800 meta-analyses relating to achievement. Routledge.

Heath, S. B. (1991). "It's about winning!": The language of knowledge in baseball. In L. B. Resnick, J. M. Levine \& S. D. Teasley (Eds.), Perspectives on socially shared cognition (pp. 101-124). American Psychological Association.

Heath, S. B. (1993). Inner city life through drama: Imagining the language classroom. TESOL Quarterly, 27(2), 177-192. https://doi.org/10.2307/3587142

Heath, S. B. (1999). Dimensions of language development: Lessons from older children. In A. S. Masten (Ed.), Cultural processes in child development: The Minnesota symposium on child psychology (Vol. 29, pp. 59-75). Lawrence Erlbaum.

Helliwell, J.F., Layard, R., \& Sachs, J. (2013). World happiness report 2012. https://worldhappiness.report/ed/2012/

Holder, M. D., Passmore, H.-A., Broom, C., Berg, S., Li, E., Hickey, R., \& Martin, C. (2016). Walls of wellbeing (WOWs): a pilot study of a new methodology to explore children's and adolescents' perceived sources of happiness. International Journal of Applied Positive Psychology, 1(1), 91-106. https://doi.org/10.1007/s41042-017-0008-9

Jager, I. J., Vulink, N. C. C., Bergfeld, I. O., van Loon, A. J. J. M., \& Denys, D. A. J. P. (2021). Cognitive behavioral therapy for misophonia: A randomized clinical trial. Depression \& Anxiety, 38, 708-718. https://doi.org/10.1002/da.23127

Kashdan, T. B., Ferssizidis, P., Collins, R. L., \& Muraven, M. (2010). Emotion differentiation as resilience against excessive alcohol use. Psychological Science, 21(9), 1341-1347. https://doi.org/10.1177/0956797610379863

Kassim, M. A. M., Pang, N. T. P., Kamu, A., Arslan, G., Mohamed, N. H., Zainudin, S. P., Ayu, F., \& Ho, C. M. (2021). Psychometric properties of the coronavirus stress measure with Malaysian young adults: Association with psychological inflexibility and psychological distress. International Journal of Mental Health and Addiction. Advance online publication. https://doi.org/10.1007/s11469-021-00622-y 
Kern, M. L., Benson, L., Steinberg, E. A., \& Steinberg, L. (2016). The EPOCH measure of adolescent well-being. Psychological Assessment, 28(5), 586-597. https://doi.org/10.1037/pas0000201

Kern, M. L., Waters, L. E., Adler, A., \& White, M. A. (2015). A multidimensional approach to measuring wellbeing in students: Application of the PERMA framework. The Journal of Positive Psychology, 10(3), 262-271. https://doi.org/10.1080/17439760.2014.936962

Kessler, R. C., Avenevoli, S., \& Merikangas, K. R. (2001). Mood disorders in children and adolescents: An epidemiologic perspective. Biological Psychiatry, 49(12), 1002-1014. https://doi.org/10.1016/s0006$\underline{3223(01) 01129-5}$

Keyes, C. L. (2007). Promoting and protecting mental health as flourishing: A complementary strategy for improving national mental health. American Psychologist, 62(2), 95-108. https://doi.org/10.1037/0003066x.62.2.95

Kieling, C., Baker-Henningham, H., Belfer, M., Conti, G., Ertem, I., Omigbodun, O., Rohde, L. A., Srinath, S., Ulkuer, N., \& Rahman, A. (2011). Child and adolescent mental health worldwide: evidence for action. The Lancet, 378(9801), 1515-1525. https://doi.org/10.1016/S0140-6736(11)60827-1

King, P. E., Dowling, E. M., Mueller, R. A., White, K., Schultz, W., Osborn, P., Dickerson, E., Bobek, D. L., Lerner, R. M., Benson, P. L., \& Scales, P. C. (2005). Thriving in adolescence: the voices of youth-serving practitioners, parents, and early and late adolescents. The Journal of Early Adolescence, 15(1), 94-112. https://doi.org/10.1177\%2F0272431604272459

Lansdown, G. (2004). Participation and young children. Early Childhood Matters, 103, 4-14. https:/earlychildhoodmatters.online/wp-content/uploads/2019/06/ECM1032004 Young_childrens_participation_Rhetoric_or_growing_reality.pdf

Larson, R. W. (1983). Adolescents' daily experience with family and friends: Contrasting opportunity systems. Journal of Marriage and Family, 45(4), 739-750. https://doi.org/10.2307/351787

Larson, R. W. (2000). Toward a psychology of positive youth development. American Psychologist, 55(1), 170. https://doi.org/10.1037/0003-066X.55.1.170

Larson, R. W., \& Kleiber, D. (1993). Daily experience of adolescents. In P. Tolan \& B. Cohler (Eds.), Handbook of clinical research and practice with adolescents (pp. 125-145). John Wiley \& Sons.

Lawrence, D., Johnson, S., Hafekost, J., Boterhoven de Haan, K., Sawyer, M., Ainley, J., \& Zubrick, S. (2015). The mental health of children and adolescents: Report on the second Australian Child and Adolescent Survey of Mental Health and Wellbeing. Commonwealth of Australia. https://www.health.gov.au/resources/publications/the-mental-health-of-children-and-adolescents

Learning Metrics Task Force (2013), Towards Universal Learning: What Every Child Should Learn. UNESCO and Center for Universal Education at Brookings.

Lerner, J. V., Phelps, E., Forman, Y. E., \& Bowers, E. P. (2009). Positive youth development. In R. M. Lerner \& L. Steinberg (Eds.), Handbook of adolescent psychology: Individual bases of adolescent development (pp. 524558). John Wiley \& Sons.

Liang, L., Ren, H., Cao, R., Hu, Y., Qin, Z., Li, C., \& Mei, S. (2020). The effect of COVID-19 on youth mental health. Psychiatric Quarterly, 91(3), 841-852. https://doi.org/10.1007/s11126-020-09744-3

Liau, A. K., Liau, A. W. L., Teoh, G. B. S., \& Liau, M. T. L. (2003). The case for emotional literacy: The influence of emotional intelligence on problem behaviours in Malaysian secondary school students. Journal of Moral Education, 32(1), 51-66. https://doi.org/10.1080/0305724022000073338

Mäkelä, T.-M., Kankaanranta, M., \& Gallagher, C. (2014). Involving students in the redesign of learning environments conducive to learning and well-being. In Proceedings of the 6th Annual Architectural Research Symposium in Finland 2014: Designing and planning the built environment for human well-being (pp. 268282). Department of Architecture, University of Oulu, Finland.

Malboeuf-Hurtubise, C., Léger-Goodes, T., Mageau, G. A., Joussemet, M., Herba, C., Chadi, N., Lefrançois, D., Camden, C., Bussières, E. L., Taylor, G., Ethier, M. A., \& Gagnon, M. (2021). Philosophy for children and mindfulness during COVID-19: Results from a randomized cluster trial and impact on mental health in elementary school students. Progress in Neuro-Psychopharmacology and Biological Psychiatry, 107, 110260. https://doi.org/10.1016/j.pnpbp.2021.110260

Marques de Miranda, D., da Silva Athanasio, B., Sena Oliveira, A. C., \& Simoes-e-Silva, A. C. (2020). How is 
COVID-19 pandemic impacting mental health of children and adolescents? International Journal of Disaster Risk Reduction, 51, 101845. https://doi.org/10.1016/j.ijdrr.2020.101845

Mashford-Scott, A., Church, A., \& Tayler, C. (2012). Seeking children's perspectives on their well-being in early childhood settings. International Journal of Early Childhood, 44(3), 231-247. https://doi.org/10.1007/s13158012-0069-7

Miles, M. B., \& Huberman, A. M. (1994). Qualitative data analysis: An expanded sourcebook (2nd ed.). SAGE Publications.

Oades, L. G. (2017). Wellbeing literacy: The missing link in positive education. In M. White, G. Slemp, \& A. Murray (Eds.), Future directions in well-being (pp. 169-173). Springer.

Oades, L. G., \& Johnston, A. L. (2017). Wellbeing literacy: The necessary ingredient in positive education. International Journal of Psychology and Behavioral Sciences, 3(5), 555621. https://www.doi.org/10.19080/PBSIJ.2017.03.555621

Oades, L. G., Ozturk, C., Hou, H., \& Slemp, G. R. (2020). Wellbeing literacy: A language-use capability relevant to wellbeing outcomes of positive psychology intervention. The Journal of Positive Psychology, 15(5), 696700. https://doi.org/10.1080/17439760.2020.1789711

Olesen, S. P., \& Eskelinen, L. (2011). Short narratives as a qualitative approach to effects of social work interventions. Nordic Social Work Research, 1(1), 61-77. https://doi.org/10.1080/2156857x.2011.562038

Organisation for Economic Co-operation and Development. (2015). Skills for social progress: The power of social and emotional skills. OECD Publishing. http://doi.org/10.1787/9789264226159-en

Owens, R., \& Waters, L. (2020). What does positive psychology tell us about early intervention with children and adolescents? A review of the impact of PPIs with young people. Journal of Positive Psychology, 15(5), 588597. https://doi.org/10.1080/17439760.2020.1789706

Proctor, C., Tsukayama, E., Wood, A. M., Maltby, J., Eades, J. F., \& Linley, P. A. (2011). Strengths gym: The impact of a character strengths-based intervention on the life satisfaction and wellbeing of adolescents. The Journal of Positive Psychology, 6(5), 377-388. https://doi.org/10.1080/17439760.2011.594079

Quinlan, D. M., Swain, N., Cameron, C., \& Vella-Brodrick, D. A. (2015). How "other people matter" in a classroom-based strengths intervention: Exploring interpersonal strategies and classroom outcomes. The Journal of Positive Psychology, 10(1), 77-89. https://doi.org/10.1080/17439760.2014.920407

Riessman, C. K. (2008). Narrative methods for the human sciences. SAGE Publications.

Riessman, C. K., \& Quinney, L. (2005). Narrative in social work: A critical review. Qualitative Social Work, 4, 391-412. http://doi.org/10.1177/1473325005058643

Ritchhart, R., Church, M., \& Morrison, K. (2011). Making thinking visible: How to promote engagement, understanding, and independence for all learners. Jossey-Bass.

Roffey, S. (2006). Circle time for emotional literacy. Paul Chapman Publishing.

Seligman, M. E. P. (2018). PERMA and the building blocks of well-being. Journal of Positive Psychology, 13(4), 333-335. https://doi.org/10.1080/17439760.2018.1437466

Seligman, M., Ernst, R., Gillham, J., Reivich, K., \& Linkin, M. (2009). Positive education: Positive psychology and classroom interventions. Oxford Review of Education, 35, 293-311. https://doi.org/10.1080/03054980902934563

Shoshani, A., Steinmetz, S., \& Kanat-Maymon, Y. (2016). Effects of the Maytiv positive psychology school program on early adolescents' well-being, engagement, and achievement. Journal of School Psychology, 57, 73-92. https://doi.org/10.1016/j.jsp.2016.05.003

Slemp, G., Kern, P., Chin, T.C., Soukous, C., Loton, D., Oades, L., Vella-Brodrick, D., \& Waters, L. (2017). Positive education in Australia. In E. Frydenberg, A. Martin \& R. Collie (Eds), Social emotional learning in the Australasian context (pp. 101-122). Springer.

Sprang, G., \& Silman, M. (2013). Posttraumatic stress disorder in parents and youth after health-related disasters. Disaster Medicine and Public Health Preparedness, 7(1), 105-110. https://doi.org/10.1017/dmp.2013.22

Stallman, H. M., Ohan, J. L., \& Chiera, B. (2018). The role of social support, being present, and self-kindness in university student psychological distress. Australian Psychologist, 53(1), 52-59. https://doi.org/10.1111/ap.12271

Stewart, S. L., Vasudeva, A. S., Van Dyke, J. N., \& Poss, J. W. (2021). Child and youth mental health needs and service utilization during COVID-19. Traumatology. Advance online publication. 
https://doi.org/10.1037/trm0000345

Stutzer, A. and B.S. Frey (2010). Recent advances in the economics of individual subjective well-being. Social
Research:
An
International
Quarterly,
$77(2)$,
679-714.

https://papers.ssrn.com/sol3/papers.cfm?abstract id=1579572

Tominey, S. L., \& McClelland, M. M. (2011). Red light, purple light: Findings from a randomized trial using circle time games to improve behavioral self-regulation in preschool. Early Education and Development, 22(3), 489519. https://doi.org/10.1080/10409289.2011.574258

Waters, L. (2011). A review of school-based positive psychology interventions. Australian Educational and Developmental Psychologist, 28(2), 75-90. https://doi.org/10.1375/aedp.28.2.75

Waters, L. (2015). Why Positive Education? Teaching and Learning Network, 22(3), 16-19.

Waters, L. (2019). Searching for wellbeing in schools: A new framework to guide the science of positive education. Journal of Educational Psychological Research, 1(2), 1-8. https://doi.org/10.33140/jepr.01.02.02

Waters, L. (2021). Positive education pedagogy: Shifting teacher mindsets, practice and language to make wellbeing visible in classrooms. In M. Kern \& M. Wehmeyer (Eds.), The Palgrave handbook of positive education (pp. 137-164). Palgrave Macmillan.

Waters, L., Allen, K.-A., \& Arslan, G. (2021). Adversarial growth in adolescents returning to school after COVID19 school closure. Frontiers in Psychology, 12, 643443. https://doi.org/10.3389/fpsyg.2021.643443

Waters, L., Barsky, A., Ridd, A., \& Allen, K. (2015). Contemplative education: a systematic, evidence-based review of the effect of meditation interventions in schools. Educational Psychology Review, 27(1), 103-134. https://doi.org/10.1007/s10648-014-9258-2

Waters, L., \& Loton, D. (2019). SEARCH: a meta-framework and review of the field of positive education. International Journal of Applied Positive Psychology, 4, 1-46. https://doi.org/10.1007/s41042-019-00017-4

Waters, L., Loton, D., \& Dussert, D. (2021). How do young children understand and action their own wellbeing? Positive psychology, student voice, and wellbeing literacy in early childhood. The International Journal of Applied Positive Psychology. Advance online publication. https://doi.org/10.1007/s41042-021-00056-w

Waters, L., Sun, J., Rusk, R., Cotton, A., \& Arch, A. (2017). Positive education: Visible wellbeing and the five domains of positive functioning. In M. Slade., L. Oades., \& A. Jarden (Eds.), Wellbeing, recovery and mental health (pp. 245-264). Cambridge University Press.

Weare, K. (2004). Developing the emotionally literate school. Paul Chapman Publishing.

Westerhof, G. J., \& Keyes, C. L. (2010). Mental illness and mental health: The two continua model across the lifespan. Journal of Adult Development, 17(2), 110-119. https://doi.org/10.1007/s10804-009-9082-y

World Health Organization. (2020). Helping children cope with stress during the 2019 n-CoV outbreak. https://www.who.int/docs/default-source/coronaviruse/helping-children-cope-with-stressprint.pdf?sfvrsn=f3a063ff 2

World Health Organization, \& United Nations Educational, Scientific and Cultural Organization. (2018). Global standards for health promoting schools: Concept note. https:/www.who.int/publications/i/item/globalstandards-for-health-promoting-schools

World Health Organization, \& United Nations Educational, Scientific and Cultural Organization. (2021). Making every school a health-promoting school: global standards and indicators. https://apps.who.int/iris/bitstream/handle/10665/341907/9789240025059-eng.pdf

World Health Organization, United Nations Educational, Scientific and Cultural Organization, World Bank, \& United Nations Children's Fund. (2000). Focusing resources on effective school health: a FRESH start to enhancing the quality and equity of education. https://www.unscn.org/en/resource-center/archive/nutritionthrough-lifecycle/nutrition-youth?idnews=1613

Yeasmin, S., Banik, R., Hossain, S., Hossain, M. N., Mahumud, R., Salma, N., \& Hossain, M. M. (2020). Impact of COVID-19 pandemic on the mental health of children in Bangladesh: A cross-sectional study. Children and Youth Services Review, 117, 105277. https://doi.org/10.1016/j.childyouth.2020.105277

Zentall, S. R., \& Morris, B. J. (2010). "Good job, you're so smart": The effects of inconsistency of praise type on young children's motivation. Journal of Experimental Child Psychology, 107(2), 155-163. https://doi.org/10.1016/i.jecp.2010.04.015

Zhou, S.-J., Zhang, L.-G., Wang, L.-L., Guo, Z.-C., Wang, J.-Q., Chen, J.-C., Liu, M., Chen, X., \& Chen, J.-X. 
(2020). Prevalence and socio-demographic correlates of psychological health problems in Chinese adolescents during the outbreak of COVID-19. European Child \& Adolescent Psychiatry, 29(6), 749-758. https://doi.org/10.1007/s00787-020-01541-4 